\title{
Research Communication Influence of Interleukin IL-2 and IL-12 + IL-18 on Surface Expression of Immunoglobulin-Like Receptors KIR2DL1, KIR2DL2, and KIR3DL2 in Natural Killer Cells
}

\author{
Slawomir Chrul, Ewa Polakowska, Agnieszka Szadkowska, and Jerzy Bodalski \\ Department of Pediatrics, Medical University, Sporna 36/50, Lodz 91-738, Poland
}

Received 5 December 2005; Revised 22 March 2006; Accepted 25 April 2006

Natural killer (NK) cells express killer cell inhibitory receptors (KIRs) that recognize polymorphic class I MHC molecules. In the present study, we analyze the modulatory effect of IL-2 alone or a combination of IL-12 with IL-18 on surface expression of killer cell immunoglobulin-like receptors KIR2DL1, KIR2DL2, and KIR3DL2 in NK cells. Thus, it was found that IL-2 causes a significant increase in the proportion of cells with given studied receptors. Stimulation by a mixture of IL-12 and IL-18 caused significant increase in the fraction of cells with the KIR2DL1 and KIR2DL2, however no significant change in the percentage of cells with KIR3DL2 receptor on their surface was observed. The results of the study show the presence of KIRs on both resting and activated NK cells, this may suggest that KIRs have also an important role in the regulatory processes after activation of this subpopulation of cells.

Copyright (c) 2006 Slawomir Chrul et al. This is an open access article distributed under the Creative Commons Attribution License, which permits unrestricted use, distribution, and reproduction in any medium, provided the original work is properly cited.

\section{INTRODUCTION}

Natural killer (NK) cells are a key component of an innate immune defense $[1,2]$. They are involved both in the control of viral infections and elimination of tumor cells. NK cells are a subset of mononuclear cells which have long been suspected of playing an immunoregulatory role in the prevention of autoimmune diseases (reviewed in [3]). Their activity can be described as nonadaptive and independent of $\mathrm{MHC}$ restriction $[4,5]$. A variety of $\mathrm{NK}$ cell functions such as cytotoxicity, proliferation, chemotaxis, and cytokine production are modulated by regulatory cytokines including IFN- $\alpha$, IL-2, IL-12, IL-18, IL-10, and TNF [6, 7]. In addition, NK cells secrete cytokines, such as IFN and TNF, during infection and inflammation [6]. NK cells express members of a multigenic family of killer cell inhibitory receptors (KIRs) that recognize polymorphic class I MHC molecules on target cells protecting healthy cells from destruction while enabling killing of abnormal cells [8-10]. Based on the number of extracellular Ig domains, two families of KIR can be distinguished and they have either short (S) or long (L) intracytoplasmic tails which transduce activating and inhibitory signals, respectively. KIR2D (with two Ig domains) interacts with HLA-C allotypes, while KIR3D (with three Ig domains) interacts with HLA-B molecules that display the Bw4 epitope (KIR3DL1) or with HLA-A alleles (KIR3DL2). Functional analysis showed that HLA-A3 or HLA-A11 molecules could inhibit lysis mediated by NK cells expressing the KIR3DL2 $[11,12]$. Genes encoding KIR2DL1 and KIR2DL2/3 are present in virtually all Caucasoid individuals $[13,14]$. How could KIR-expressing cells play a role in initiating autoimmunity? Recognition of HLA class 1 by activating KIRs on both natural killer and T-cell subsets may affect the immune response through the secretion of interferon-document and other possible T-helper 1 cytokine [15]. KIRs may also be important in the regulation of peripheral tolerance of T-cell subsets. Activating KIRs, combined with insufficient regulation of T-cell autoreactivity by inhibitory KIR, may facilitate the activation of autoreactive $\mathrm{T}$ cells that are breaking tolerance for self-antigens. A genetic imbalance between activating and inhibitory KIR genes may influence the pathogenesis of autoimmune diseases, either via upregulated activation or lack of inhibition or both.

A variety of data indicate that self-tolerance of NK cells can be broken in some instances by culturing these cells in high doses of IL-2 [16-18]. NK cells are known to be highly responsive to many biological agents including cytokines such as IL-2, IL-12, and IL-15 and interferons (IFNs), 
and to rapidly increase their cytolytic, secretory, proliferative, and other functions upon stimulation with these agents. Cytolytic activity of NK cells is augmented by IL-2 and IL15 through the IL-2Rb chain (CD122) [19]. IL-2 potentates both growth and cytotoxic functions of NK cells with rapid activation of CD69 antigen [20]. Interleukin 18(IL-18) was discovered as an interferon- $\gamma$ (IFN- $\gamma$ )-inducing factor and plays an important role in NK cell activation [21]. IL-18 similarly to IL-12, augments NK activity through the induction of constitutively expressed IL-18 receptor (IL-18R) on NK cells [22]. IL-2 alone, or in combination with IL-12 or IL-18, has a strong ability to induce NK cell responses [23]. Interestingly, NK cells stimulated with IL-12/IL-18 secrete large amounts of IFN-, whereas NK cells grown in IL-2 or IL-15 do not [24]. Also, a striking synergy between IL-12 and IL-18 was observed in different model systems [25-29]. The reports on the effect of the above discussed cytokines on the presentation of KIRs on NK cells surface are scarce. The authors usually, among selected immunological parameters, evaluate the reaction of the KIR2DL1 receptor after stimulation with IL-2 [30-32]. These interactions seem highly interesting since the involvement of these KIRs in pathological reactions was proved. Abnormal presentation of the KI2DL1 may contribute to one of immunological deficiency syndromes [33]. The KIR2DL2 receptors are connected with the pathogenesis of sclerodermia [34] and the KIR3DL2 receptors with Sezary syndrome [35]. Lymphoproliferative disease of granular lymphocytes (LDGL) is associated with the increased activatingto-inhibitory KIR ratio [36]. The decreased activation potential of NK cells associated with KIR/HLA genotypes may predispose to microscopic polyangiitis, possibly through insufficient resistance against infections [37].

In the present study, we analyze the modulatory effect of IL-2 alone or a combination of IL-12 with IL-18 on surface expression of killer cell immunoglobulin-like receptors KIR2DL1, KIR2DL2, and KIR3DL2 in NK cells.

\section{MATERIAL AND METHODS}

The study was approved by the Local Ethical Committee and a written consent was given for all participants according to the Declaration of Helsinki. Heparinized venous blood was taken from 20 Caucasoid healthy controls identified as follows: 8 females and 12 males with a mean age \pm SD of $7.5 \pm 2.5$ years

\section{Isolation of NK cells}

Peripheral blood mononuclear cells (PBMC) were isolated from buffy coats after density gradient centrifugation over Histopaque 1077 (Sigma-Aldrich, Inc, St Louis, Mo, USA). For further immunomagnetic separation of NK cells from the PBMC subjects, the magnetic cell separation (MACS) system (Miltenyi Biotech, Gladbach, Germany) was used. This method is an indirect magnetic labeling system for depletion of human T cells, B cells, and myeloid cells from PBMC to enrich untouched NK cells (negative selection). Non-NK cells were indirectly labeled with a cocktail of biotin-conjugated monoclonal antibodies against CD3, CD4, CD14, CD15, CD19, CD36, CD123, and with Glycophorin A as primary labeling reagent, and antibiotin monoclonal antibodies conjugated to MicroBeads, as a secondary labeling reagent. The magnetically labeled non-NK cells were depleted by retaining them in a column in the magnetic field while the unlabeled NK cells passed through the column. $\mathrm{Pu}-$ rification of $\mathrm{NK}$ cells was executed according to the manufacturer's directions. After isolation, NK cells were stained with fluorochrome-conjugated antibodies directed against cell surface antigens anti-CD3-FITC, CD16 + 56PE (BD Biosciences, Immunocytometry Systems, San Jose, Calif, USA). FACS analyses were performed using FACSCalibur and CellQuest software (BD Biosciences, Immunocytometry Systems, San Jose, Calif, USA). Purity of separated cells was $>95 \%$.

\section{NK cells culture in vitro}

Freshly purified NK cells $\left(1 \times 10^{6} / \mathrm{mL}\right)$ were cultured in complete RPMI 1640 medium containing 25 mM HEPES, 2 mM L-glutamine, $100 \mu \mathrm{g} / \mathrm{mL}$ streptomycin, $100 \mathrm{U} / \mathrm{mL}$ penicillin, $10 \mathrm{mM}$ sodium pyruvate solution (Sigma-Aldrich, Inc, St Louis, Mo, USA) and 10\% heat-inactivated FCS (Invitrogen, Carlsbad, USA) without any exogenous cytokine. NK cells were incubated in humidified $5 \% \mathrm{CO}_{2}$ atmosphere at $37^{\circ} \mathrm{C}$ for 72 hours in the presence or absence of recombinant human cytokines. For activation, purified NK cells were incubated with IL-2 (10 ng/mL) or IL-12 (10 ng/mL) and IL18 (100 ng/mL). Purified rhIL-2 was provided by SeromedBiochrom (Berlin, Germany). Purified rhIL-12 was obtained from Peprotech EC (London, UK). Purified rhIL-18 was provided by ProSpec-Tany TechnoGene (Rehovot, Israel). All cytokines were endotoxin free.

\section{Immunofluorescence staining and FACS analysis}

After 72 hours, cultured NK cells were washed with PBS, stained, and analyzed phenotypically. The following FITC-, PE-, PerCP- or tricolour-labeled antibody specificities were used for the analysis of cell surface markers, CD69-PECy, CD158a (KIR2DL1)-FITC, CD158b (KIR2DL2)-PE (BD Pharmingen San Diego, Calif, USA). Cells were stained with fluorochrome-conjugated antibodies directed against cell surface antigens according to the manufacturer's instruction. For staining of KIR3DL2, indirect immunofluorescence method was used. Cells were incubated first with unconjugated Q66 mAb ( anti-p140 IgM, KIR3DL2), a gift from Daniela Pende (Istituto Nazionale per la Ricerca sul Cancro, Genova, Italia), for 60 minutes at room temperature, washed, and incubated with PE-conjugated goat antimouse IgM antibodies (Southern Biotechnology Associates, Birmingham, Ala, USA) for 30 minutes at room temperature. After washing, cells were analyzed by flow cytometry.

FACS analysis was performed using FACSCalibur flow cytometry with Cell Quest software (Becton Dickinson, Immunocytometry Systems, San Jose, Calif, USA). 


\section{Measurement of NK cell cytokine protein in cell culture supernatants}

After 72 hours, cell-free culture supernatants were harvested, centrifuged to remove all cells and debris, and frozen at $-70^{\circ} \mathrm{C}$ for later analysis with cytokines by ELISA. Supernatants underwent only one freeze-thaw cycle before quantification by ELISA. Culture supernatants were tested in duplicate.

The production of IFN- $\gamma$ protein by NK cells was measured from cell-free culture supernatants with commercial ELISA kits (BioSource International, Camarillo, Calif, USA), following the manufacturers' instructions.

\section{Statistical analysis}

The differences between groups were analyzed by Wilcoxon signed rank test, the Mann-Whitney U-test and, if appropriate, by paired or unpaired $t$ test. $P<.05$ was considered to be statistically significant. All data were collected and analyzed using the Statistica 6.0 program (StatSoft Inc, Tulsa, Okla, USA).

\section{RESULTS}

\section{Evaluation of NK cells stimulation}

Stimulation of NK cells was measured by two methods. First, the concentration of IFN- $\gamma$ in supernatant was determined. In the control group the median of IFN $-\gamma$ concentration was $4 \mathrm{pg} / \mathrm{mL}$. This value significantly increased after stimulation by IL-2 to $904 \mathrm{pg} / \mathrm{mL}$, and after stimulation by a mixture of IL-12 + IL-18 up to $1000 \mathrm{pg} / \mathrm{mL}$.

Secondly, an increase in a number of NK cells with CD69 antigen on their surface was determined. As compared to $10 \%$ in cells cultured without stimulating cytokines, after IL2 the number of cells increased, on average, to $82 \%$ and after a mixture of IL-12 + IL-18 to $47 \%$. Both values were significantly different from the control value. Thus, a sufficient level of NK cells stimulation was achieved; this condition could be used to assess the effect on the studied KIRs.

\section{Expression of KIRs on NK cells after stimulation with IL-2 or mixture of IL-12 and IL-18}

The expression of KIRs was determined using two methods. First, a change in the number of NK cells with KIR2DL1, KIR2DL2, KIR3DL3 receptors on their surface was evaluated. Then, based on an assumption that the number of receptors on the surface of one cell is reflected in the number of antibodies binding to these receptors, distribution of the cells population was evaluated based on the intensity of fluorescence. Median of the studied distributions was the compared parameter.

Thus, it was found that IL-2 causes a significant increase in the proportion of cells with given receptors on their surface, KIR2DL1, KIR2DL2, and KIR3DL2: by $30 \%$ versus $22 \%$ $(P<.0001), 37 \%$ versus $30 \%(P<.0001)$, and $24 \%$ versus $14 \%(P<.0001)$, respectively. Stimulation by a mixture of
IL-12 + IL-18 caused significant increase in the fraction of cells with the studied receptors on their surface, KIR2DL1 and KIR2DL2: by $26 \%$ versus $22 \%(P<.005)$ and 33\% versus $30 \%(P<.005)$, respectively (Figure 1$)$. However, no significant change in the percentage of cells with KIR3DL2 receptor on their surface was observed ( $15 \%$ versus $14 \%, P=.36)$.

The analysis of distribution of the fluorescence intensity revealed that IL-2 also caused significant increase in the number of the KIR2DL1 and KIR2DL2 receptors on NK cells: 55 versus $33(P<.005)$ and 284 versus $209(P<.005)$, respectively (Figure 2 ). Likewise, stimulation with a mixture of IL-12 + IL-18 caused an increase in the number of these receptors: 40 versus $33(P<.005)$ and 250 versus $209(P<$ $.005)$, respectively. At the same time IL-2 had a significant strong effect that resulted in the increase in the number of cells with the KIR2DL1 receptor on their surface $(P<.05)$, and the increase in the number of these receptors on NK cells surface $(P<.05)$ as compared to IL-12 + IL-18. Neither IL-2, nor a mixture of cytokines IL-12 + IL-18, affected the number of the KIR3DL2 receptors on one NK cells surface.

\section{DISCUSSION}

The population of NK cells, according to definition, is characterised by autonomous cytotoxic ability. The principle of biological systems functioning is based on a series of safety measures operating in every case of potential autodestruction of the organism. Numerous publications of recent years have shown nonhomogeneity of NK cells population. The presence of regulatory and effector subpopulations has been documented [38, 39], as well as connection between the process of NK cells activation with the activation of antigen presenting cells $[40,41]$. At the same time numerous reports confirm the presence of receptors on the surface of NK cells which after binding to specific ligand play an important role in the stimulation and/or inhibition of cytotoxicity. Among these receptors there are KIRs with a long intraplasmatic fragment. These receptors in contact with appropriate fragment of HLA class I cause inhibition of NK cells cytotoxicity.

We have assumed that strong inhibitory action of these receptors should be used in contraregulatory processes. To verify this hypothesis, we have selected KIR2DL1 and KIR2DL2 receptors, which cover the spectrum of HLA-C antigens and HLA-A recognising KIR3DL2. NK were activated in an in vitro culture in the presence of IL-2 and a mixture of IL-12 + L-18. These cytokines, as it has been proved in numerous publications, cause strong stimulation of NK cells manifesting as, for example, increase of IFN- $\gamma$ synthesis by these cells. Despite numerous reports, which have documented the stimulatory effect of cytokines IL-2, IL-12 and IL-18 on NK cells, very few were devoted to their effect on the presentation of KIRs. The authors concentrated on the group of the KIR2DL1 receptors of NK cells after stimulation by IL2 and increase in the number of these receptors was observed [30-32]. Similarly, in our study, IL-2 was demonstrated to increase a number of the KIR2DL1 and KIR2DL2 receptors, however the reaction was much stronger in the case of KIR2DL1 [42, 43]. Both reports have not demonstrated any 

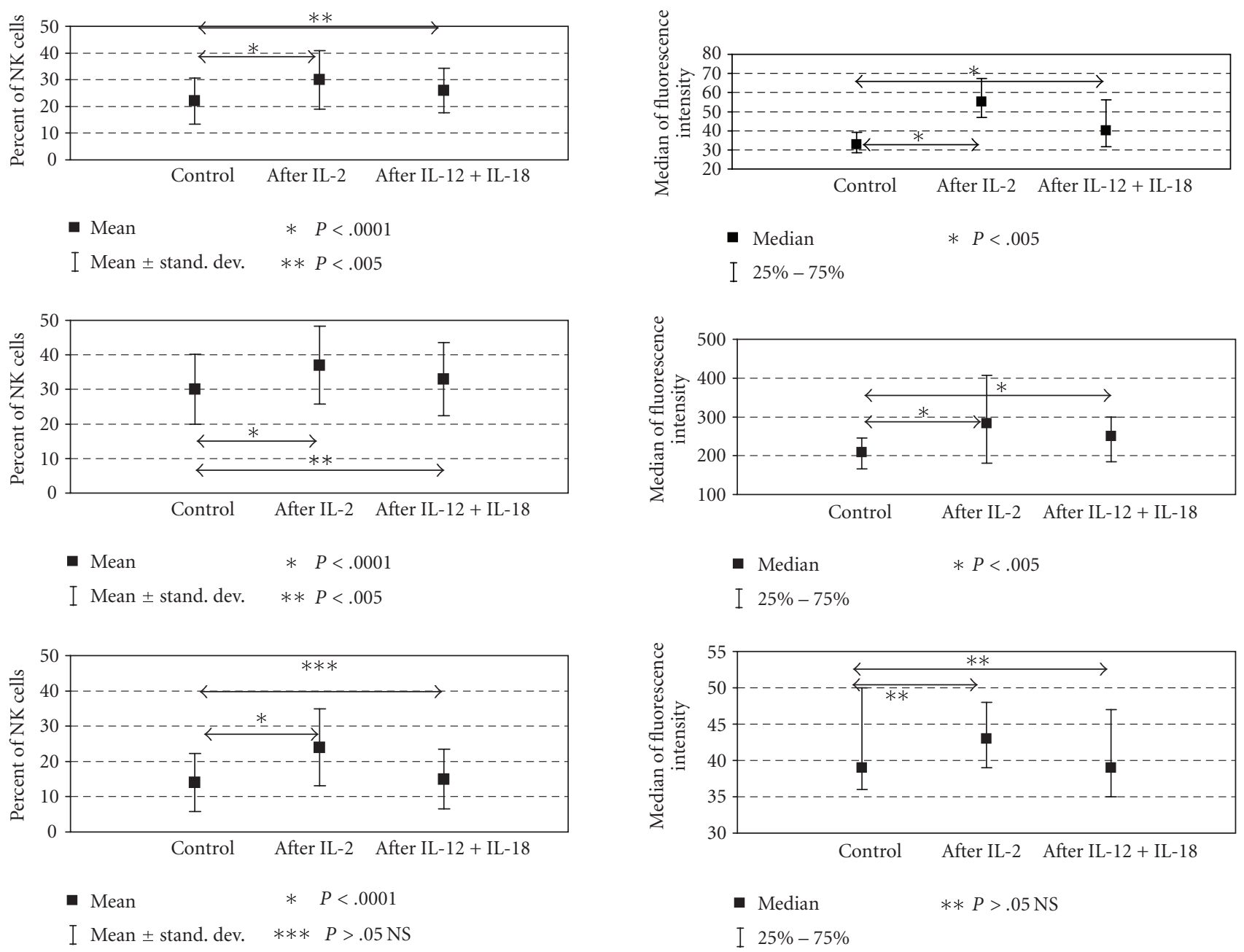

FIgURE 1: Percentage of NK cells possessing KIR2DL1, KIR2DL2, and KIR3DL2 on the surface. Both IL-2 and IL-12+IL-18 caused significant increase in the fraction of cells with KIR2DL1 and KIR2DL2 receptors whereas in the fraction of cells with KIR3DL2 receptors only IL-2 caused significant increase. $*$ denotes $P<.0001$; $* *$ denotes $P<.005 ; * *$ denotes NS (nonsignificant).

significant differences between cells populations exposed to IL-12 and IL-18, and not exposed to these cytokines [42]. The results of our study indicate that, even though the reaction of KIR receptors is smaller after IL-2, also in case of IL-2 statistically significant increase in a number of the KIR2DL1 and KIR2DL2 positive NK cells and also increase in the number of these receptors on the surface of one NK cell were seen. These differences seem to be due to the application of an optimum mixture of synergistic cytokines in our study, while in the above quoted study IL-12 and IL-18 were added to separate cultures [44-47]. It may be also resulted from the different method of NK cells separation and application of commercial antibodies in our study.

To date there have been no reports on the effect of cytokines IL-2 and IL-12+IL-18 on expression of the KIR3DL2

molecule. The study demonstrated that only IL-2 caused significant increase in a number of the cells positive for this receptor, although no change in the number of these receptors on the surface of single NK cells was seen.

The results of this study and of other reports demonstrate that cytokines causing stimulation of NK cells cause an increase in the number of NK cells with the studied KIRs on the surface, and increase in the number of KIRs. At the same time it should be noticed that this increase is much more visible in a population of NK cells stimulated by IL-2. Thus, indirectly, it was demonstrated that stimulation of NK cells is a part of an autoregulatory mechanism. Increased number of KIRs on the surface of stimulated NK cells seems to be one of the mechanisms sensitising these cells to suppression. On the other hand, different behaviour of KIRs on NK 
cells after stimulation by various cytokines shows that this process is selective. The presence of a large amount of IL-2 at the site of immunologic reaction is seen mainly in the effector stage of immunologic response. At this stage of response, contraregulatory mechanisms seem most justified. However, large amounts of cytokines IL-12 and IL-18 are seen mainly in the recognition and antigen presentation stage. In this stage NK cells contact dendritic cells (DC) and other APC cells. This is the decisive stage as to the future of NK cells reaction to the initial signals. At this stage contraregulation is necessary for transfer of signals between NK and APC cells, and activation of self-suppressor mechanisms seems to be of smaller importance. The behaviour of KIR3DL2 receptors is also interesting. Activation of IL-2 increases the number of NK cells with these receptors, however it does not increase their number on single cells. Also, there is no significant reaction after stimulation with the mixture of IL-12 + IL-18. This may suggest that although all the studied proteins belong to the same family of receptors, various cytokines stimulate their presentation to a different degree. It may indicate that particular receptors are part of different pathways of NK cells activation.

Moreover, since the KIRs have inhibitory properties and are upregulated on activated NK cells, it is likely that these receptors may play an important role in the contraregulatory processes after activation of these cells.

\section{ACKNOWLEDGMENTS}

We would like to thank Daniela Pende for her gift of antiKIR3DL2 antibodies and Wojciech Mlynarski for his help in the writing of this paper. This research project was supported by the Polish State Committee for Scientific Research (Grant 3 P05E 09523).

\section{REFERENCES}

[1] French AR, Yokoyama WM. Natural killer cells and viral infections. Current Opinion in Immunology. 2003;15(1):45-51.

[2] VanDeusen JB, Caligiuri MA. New developments in antitumor efficacy and malignant transformation of human natural killer cells. Current Opinion in Hematology. 2003;10(1):5559.

[3] Baxter AG, Smyth MJ. The role of NK cells in autoimmune disease. Autoimmunity. 2002;35(1):1-14.

[4] Trinchieri G. Biology of natural killer cells. Advances in Immunology. 1989;47:187-376.

[5] Herberman RB, Ortaldo JR. Natural killer cells: their role in defenses against disease. Science. 1981;214(4516):24-30.

[6] Biron CA, Nguyen KB, Pien GC, Cousens LP, Salazar-Mather TP. Natural killer cells in antiviral defense: function and regulation by innate cytokines. Annual Review of Immunology. 1999;17:189-220.

[7] Maghazachi AA. Chemokines, G proteins and natural killer cells. Archivum Immunologiae et Therapiae Experimentalis. 2000;48(2):65-72.

[8] Martin AM, Freitas EM, Witt CS, Christiansen FT. The genomic organization and evolution of the natural killer immunoglobulin-like receptor (KIR) gene cluster. Immunogenetics. 2000;51(4-5):268-280.
[9] Steffens U, Vyas Y, Dupont B, Selvakumar A. Nucleotide and amino acid sequence alignment for human killer cell inhibitory receptors (KIR), 1998. Tissue Antigens. 1998;51(4 pt 1):398-413.

[10] Shilling HG, Guethlein LA, Cheng NW, et al. Allelic polymorphism synergizes with variable gene content to individualize human KIR genotype. Journal of Immunology. 2002;168(5): 2307-2315.

[11] Pende D, Biassoni R, Cantoni C, et al. The natural killer cell receptor specific for HLA-A allotypes: a novel member of the p58/p70 family of inhibitory receptors that is characterized by three immunoglobulin-like domains and is expressed as a $140-\mathrm{kD}$ disulphide- linked dimer. Journal of Experimental Medicine. 1996;184(2):505-518.

[12] Hansasuta P, Dong T, Thananchai H, et al. Recognition of HLA-A3 and HLA-A11 by KIR3DL2 is peptide-specific. European Journal of Immunology. 2004;34(6):1673-1679.

[13] Toneva M, Lepage V, Lafay G, et al. Genomic diversity of natural killer cell receptor genes in three populations. Tissue Antigens. 2001;57(4):358-362.

[14] Cook MA, Moss PAH, Briggs DC. The distribution of 13 killercell immunoglobulin-like receptor loci in UK blood donors from three ethnic groups. European Journal of Immunogenetics. 2003;30(3):213-221.

[15] Mandelboim O, Kent S, Davis DM, et al. Natural killer activating receptors trigger interferon $\gamma$ secretion from $\mathrm{T}$ cells and natural killer cells. Proceedings of the National Academy of Sciences of the United States of America. 1998;95(7):3798-3803.

[16] Johansson MH, Bieberich C, Jay G, Kärre K, Höglund P. Natural killer cell tolerance in mice with mosaic expression of major histocompatibility complex class I transgene. Journal of Experimental Medicine. 1997;186(3):353-364.

[17] Kung SKP, Miller RG. Mouse natural killer subsets defined by their target specificity and their ability to be separately rendered unresponsive in vivo. Journal of Immunology. 1997; 158(6):2616-2626.

[18] Salcedo M, Andersson M, Lemieux S, Van Kaer L, Chambers BJ, Ljunggren H. Fine tuning of natural killer cell specificity and maintenance of self tolerance in MHC class I-deficient mice. European Journal of Immunology. 1998;28(4):1315-1321.

[19] Carson WE, Giri JG, Lindemann MJ, et al. Interleukin (IL) 15 is a novel cytokine that activates human natural killer cells via components of the IL-2 receptor. Journal of Experimental Medicine. 1994;180(4):1395-1403.

[20] Lanier LL, Buck DW, Rhodes L, et al. Interleukin 2 activation of natural killer cells rapidly induces the expression and phosphorylation of the Leu-23 activation antigen. Journal of Experimental Medicine. 1988;167(5):1572-1585.

[21] Okamura H, Tsutsui H, Komatsu T, et al. Cloning of a new cytokine that induces IFN- $\gamma$ production by T cells. Nature. 1995;378(6552):88-91.

[22] Hyodo Y, Matsui K, Hayashi N, et al. IL-18 up-regulates perforin-mediated NK activity without increasing perforin messenger RNA expression by binding to constitutively expressed IL-18 receptor. Journal of Immunology. 1999;162(3): $1662-1668$.

[23] Hodge DL, Schill WB, Wang JM, et al. IL-2 and IL-12 alter NK cell responsiveness to IFN- $\gamma$-inducible protein 10 by downregulating CXCR3 expression. Journal of Immunology. 2002; 168(12):6090-6098.

[24] Lauwerys BR, Garot N, Renauld JC, Houssiau FA. Cytokine production and killer activity of NK/T-NK cells derived with IL-2, IL-15, or the combination of IL-12 and IL-18. Journal of Immunology. 2000;165(4):1847-1853. 
[25] Fukao T, Matsuda S, Koyasu S. Synergistic effects of IL-4 and IL-18 on IL-12-dependent IFN- $\gamma$ production by dendritic cells. Journal of Immunology. 2000;164(1):64-71.

[26] Hofstra CL, Van Ark I, Hofman G, Kool M, Nijkamp FP, Van Oosterhout AJM. Prevention of Th2-like cell responses by coadministration of IL-12 and IL-18 is associated with inhibition of antigen-induced airway hyperresponsiveness, eosinophilia, and serum IgE levels. Journal of Immunology. 1998;161(9):5054-5060.

[27] Lauwerys BR, Renauld JC, Houssiau FA. Synergistic proliferation and activation of natural killer cells by interleukin 12 and interleukin 18. Cytokine. 1999;11(11):822-830.

[28] Tomura M, Zhou XY, Maruo S, et al. A critical role for IL-18 in the proliferation and activation of $\mathrm{NK} 1.1^{+} \mathrm{CD}^{-}$cells. Journal of Immunology. 1998;160(10):4738-4746.

[29] Yamanaka K, Hara I, Nagai H, et al. Synergistic antitumor effects of interleukin-12 gene transfer and systemic administration of interleukin-18 in a mouse bladder cancer model. Cancer Immunology Immunotherapy. 1999;48(6):297-302.

[30] Aktas E, Akdis M, Bilgic S, et al. Different natural killer (NK) receptor expression and immunoglobulin $\mathrm{E}$ (IgE) regulation by NK1 and NK2 cells. Clinical and Experimental Immunology. 2005;140(2):301-309.

[31] Draghi M, Yawata N, Gleimer M, Yawata M, Valiante NM, Parham P. Single-cell analysis of the human NK cell response to missing self and its inhibition by HLA class I. Blood. 2005; 105(5):2028-2035.

[32] Ferlazzo G, Thomas D, Lin SL, et al. The abundant NK cells in human secondary lymphoid tissues require activation to express killer cell Ig-like receptors and become cytolytic. Journal of Immunology. 2004;172(3):1455-1462.

[33] Gazit R, Garty BZ, Monselise Y, et al. Expression of KIR2DL1 on the entire NK cell population: a possible novel immunodeficiency syndrome. Blood. 2004;103(5):1965-1966.

[34] Momot T, Koch S, Hunzelmann N, et al. Association of killer cell immunoglobulin-like receptors with scleroderma. Arthritis and Rheumatism. 2004;50(5):1561-1565.

[35] Musette P, Michel L, Jean-Louis F, Bagot M, Bensussan A. Polymorphic expression of CD158k/p140/KIR3DL2 in Sézary patients. Blood. 2003;101(3):1203.

[36] Epling-Burnette PK, Painter JS, Chaurasia P, et al. Dysregulated NK receptor expression in patients with lymphoproliferative disease of granular lymphocytes. Blood. 2004;103(9): 3431-3439.

[37] Miyashita R, Tsuchiya N, Yabe T, et al. Association of killer cell immunoglobulin-like receptor genotypes with microscopic polyangiitis. Arthritis and Rheumatism. 2006;54(3):992-997.

[38] Batoni G, Esin S, Favilli F, et al. Human CD56 ${ }^{\text {bright }}$ and CD56 ${ }^{\mathrm{dim}}$ natural killer cell subsets respond differentially to direct stimulation with Mycobacterium bovis bacillus CalmetteGuérin. Scandinavian Journal of Immunology. 2005;62(6):498506.

[39] Jin Y, Damaj BB, Maghazachi AA. Human resting CD16-, $\mathrm{CD}_{16} 6^{+}$and IL-2-, IL-12-, IL-15- or IFN- $\alpha$-activated natural killer cells differentially respond to sphingosylphosphorylcholine, lysophosphatidylcholine and platelet-activating factor. European Journal of Immunology. 2005;35(9):2699-2708.

[40] Vitale M, Della Chiesa M, Carlomagno S, et al. NK-dependent DC maturation is mediated by TNF $\alpha$ and IFN $\gamma$ released upon engagement of the NKp30 triggering receptor. Blood. 2005; 106(2):566-571.

[41] Marcenaro E, Ferranti B, Moretta A. NK-DC interaction: on the usefulness of auto-aggression. Autoimmunity Reviews. 2005;4(8):520-525.
[42] Shin EC, Choi KS, Kim SJ, Shin JS. Modulation of the surface expression of CD158 killer cell Ig-like receptor by interleukin2 and transforming growth factor- $\beta$. Yonsei Medical Journal. 2004;45(3):510-514.

[43] Kogure T, Fujinaga H, Niizawa A, et al. Killer-cell inhibitory receptors, CD158a/b, are upregulated by interleukin-2, but not interferon- $\gamma$ or interleukin-4. Mediators of Inflammation. 1999;8(6):313-318.

[44] Matsumoto K, Kanmatsuse K. Interleukin-18 and interleukin12 synergize to stimulate the production of vascular permeability factor by $\mathrm{T}$ lymphocytes in normal subjects and in patients with minimal-change nephrotic syndrome. Nephron. 2000;85(2):127-133.

[45] Nakahira M, Ahn HJ, Park WR, et al. Synergy of IL-12 and IL-18 for IFN- $\gamma$ gene expression: IL-12-induced STAT4 contributes to IFN- $\gamma$ promoter activation by up-regulating the binding activity of IL-18-induced activator protein 1-. Journal of Immunology. 2002;168(3):1146-1153.

[46] Okamoto M, Kato S, Oizumi K, et al. Interleukin 18 (Il-18) in synergy with Il-2 induces lethal lung injury in mice: a potential role for cytokines, chemokines, and natural killer cells in the pathogenesis of interstitial pneumonia. Blood. 2002;99(4): 1289-1298.

[47] Tarkowski M, Chrul S, Bodalski J. The effect of IL-18 on IL12 -induced CD30 expression and IL- 4 and IFN- $\gamma$ production by allergen and PPD specific T cells. Clinical and Experimental Immunology. 2002;127(1):78-84. 


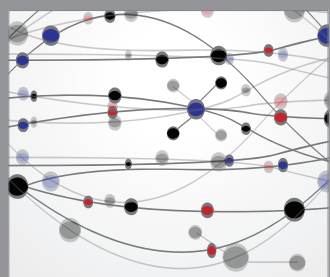

The Scientific World Journal
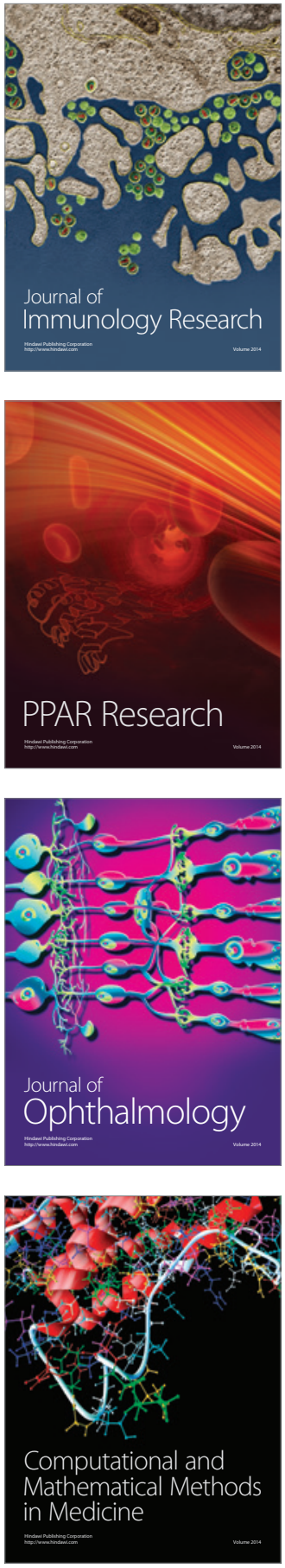

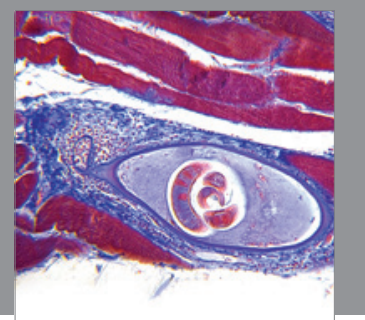

Gastroenterology

Research and Practice
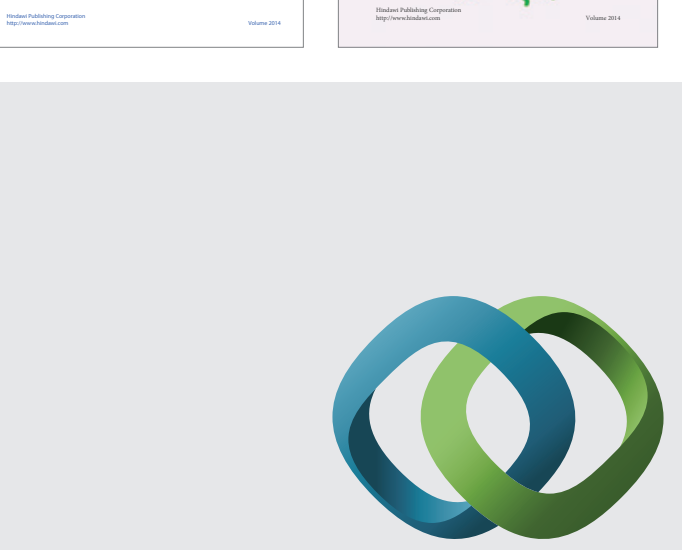

\section{Hindawi}

Submit your manuscripts at

http://www.hindawi.com
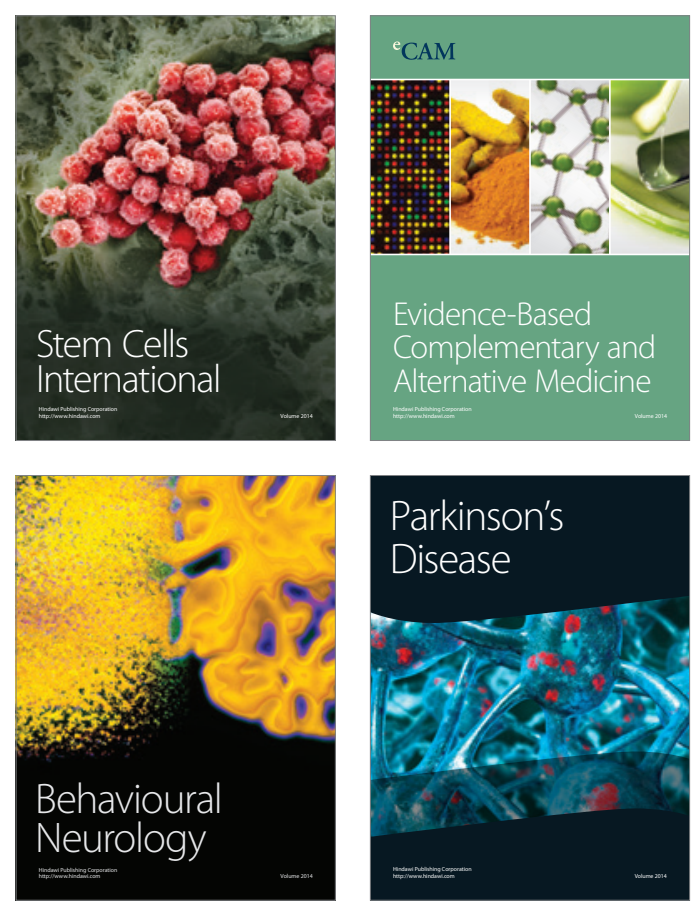

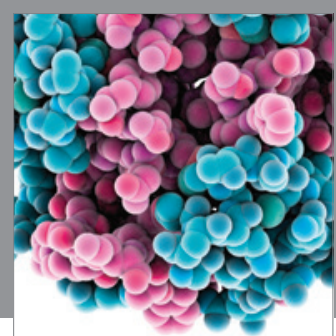

Journal of
Diabetes Research

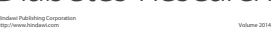

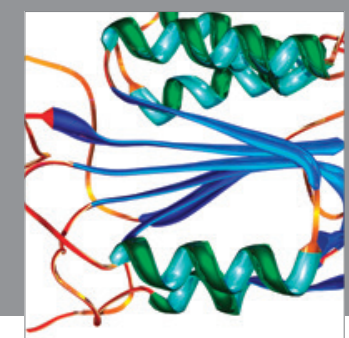

Disease Markers
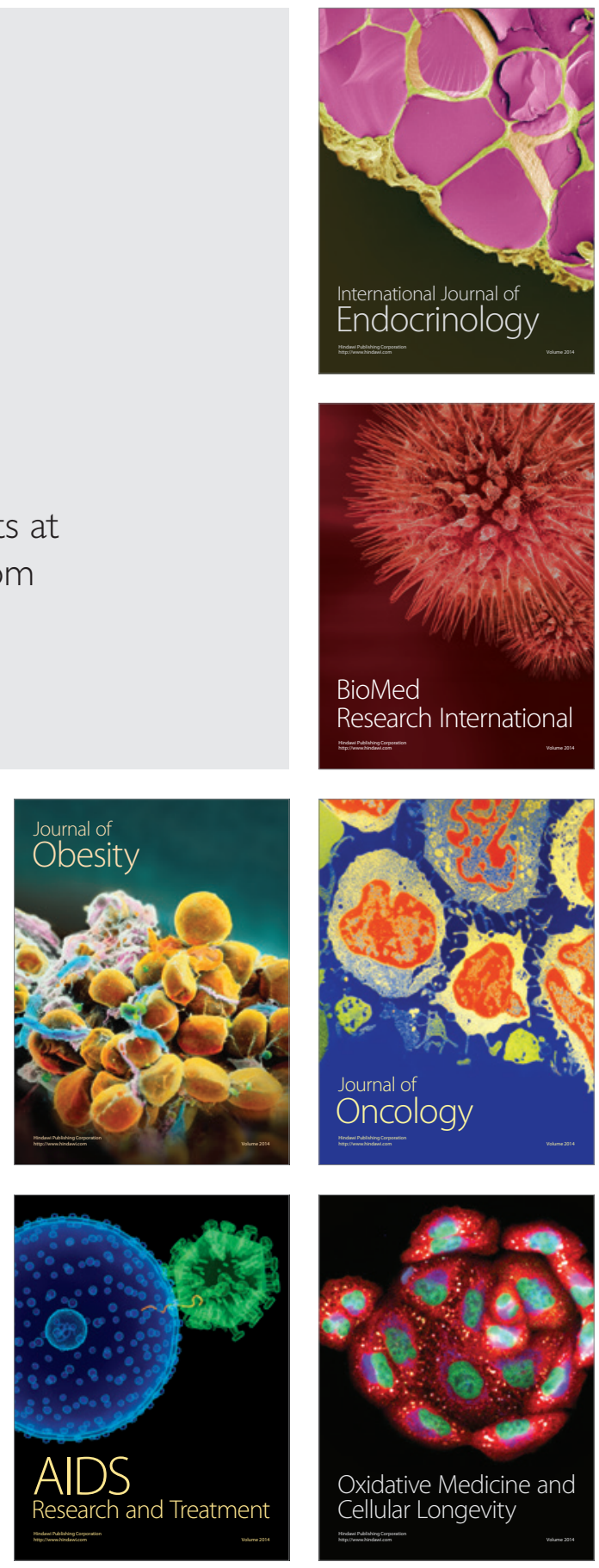